\title{
Non-typeable pneumococci circulating in Portugal are of $c p s$ type NCC2 and have genomic features typical of encapsulated isolates
}

\author{
Débora A Tavares ${ }^{1 \dagger}$, Alexandra S Simões ${ }^{1 \dagger}$, Hester J Bootsma ${ }^{2}$, Peter WM Hermans ${ }^{2,3}$, Hermínia de Lencastre ${ }^{4,5}$ \\ and Raquel Sá-Leão ${ }^{1 *}$
}

\begin{abstract}
Background: Pneumococcus is a major human pathogen and the polysaccharide capsule is considered its main virulence factor. Nevertheless, strains lacking a capsule, named non-typeable pneumococcus (NT), are maintained in nature and frequently colonise the human nasopharynx. Interest in these strains, not targeted by any of the currently available pneumococcal vaccines, has been rising as they seem to play an important role in the evolution of the species. Currently, there is a paucity of data regarding this group of pneumococci. Also, questions have been raised on whether they are true pneumococci. We aimed to obtain insights in the genetic content of NT and the mechanisms leading to non-typeability and to genetic diversity.

Results: A collection of 52 NT isolates representative of the lineages circulating in Portugal between 1997 and 2007, as determined by pulsed-field gel electrophoresis and multilocus sequence typing, was analysed. The capsular region was sequenced and comparative genomic hybridisation (CGH) using a microarray covering the genome of 10 pneumococcal strains was carried out. The presence of mobile elements was investigated as source of intraclonal variation. NT circulating in Portugal were found to have similar capsular regions, of cps type NCC2, i.e., having aliB-like ORF1 and aliB-like ORF2 genes. The core genome of NT was essentially similar to that of encapsulated strains. Also, competence genes and most virulence genes were present. The few virulence genes absent in all NT were the capsular genes, type-I and type-Il pili, choline-binding protein A (cbpA/pspC), and pneumococcal surface protein A ( $p s p A)$. Intraclonal variation could not be entirely explained by the presence of prophages and other mobile elements.
\end{abstract}

Conclusions: NT circulating in Portugal are a homogeneous group belonging to cps type NCC2. Our observations support the theory that they are bona-fide pneumococcal isolates that do not express the capsule but are otherwise essentially similar to encapsulated pneumococci. Thus we propose that NT should be routinely identified and reported in surveillance studies.

\section{Background}

Pneumococcus is a major human pathogen, causing a wide range of infections from otitis media to bacteraemia and meningitis. Its main virulence determinant is a polysaccharide capsule that surrounds pneumococcal cells, providing protection against phagocytosis [1]. Together

\footnotetext{
* Correspondence: rsaleao@itqb.unl.pt

${ }^{\dagger}$ Equal contributors

'Laboratory of Molecular Microbiology of Human Pathogens, Instituto de Tecnologia Química e Biológica (ITQB) António Xavier, Universidade Nova de Lisboa (UNL), Oeiras, Portugal

Full list of author information is available at the end of the article
}

with colony morphology, susceptibility to optochin, and bile solubility, assignment of a serotype (based on the capsular type) has been traditionally the ultimate assay to identify pneumococcus [2]. To date, more than 95 serotypes have been described and, with the exception of type 37 , the genes responsible for the expression of the capsule are located in the chromosome between the $\operatorname{dex} B$ and aliA genes (capsular region) [1,3]. The pneumococcal capsule is also the target of all currently available pneumococcal vaccines [4].

Pneumococci lacking a polysaccharide capsule are known to exist in nature and are frequent inhabitants of

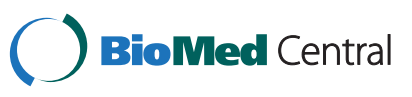


the upper respiratory tract of humans [5]. Although these isolates, often named non-typeable pneumococcus (NT), are mostly asymptomatically carried in the nasopharynx, they have also been associated with conjunctivitis outbreaks and sporadically associated with other disease manifestations including invasive disease [6-9]. Studies have suggested, using a combination of phenotypic and genotypic methods, that some of these isolates are bona-fide pneumococci and share common properties with encapsulated pneumococci $[5,10]$. Also, in vitro studies with non-encapsulated pneumococci have shown that these strains display increased adherence to epithelial tissue, increased capacity for biofilm formation, and are highly transformable [11-13]. Hence, high carriage rates combined with high transformability rates may provide NT with the features needed to play an important role in the evolution of pneumococcus as recently proposed by Chewapreecha, et al. [14].

In a previous study, we have described the population structure of NT strains in Portugal and identified major lineages associated with them [5]. In parallel, others have identified the same lineages in circulation in other geographical settings and the capsular region of NT has been characterised [10,15-17]. Based on the capsular region, NT have been proposed to be divided in two groups: Group I includes isolates with a disrupted or non-functional capsular locus and Group II includes isolates with genes not found in conventional capsular types [17]. Group II NT have been proposed to be further divided into cps types NCC1, when isolates have the $p s p K$ gene (pneumococcal surface protein Korea, also referred to as $n s p A$, non-typeable pneumococcal surface protein A), encoding for a novel pneumococcal surface protein with several features suggesting a role in cell adhesion and enhanced colonisation, and NCC2, when isolates have both the aliB-like ORF1 and aliB-like ORF2 genes, predicted to encode for lipoproteins [15-18]. A cps type NCC3 has also been described for isolates with aliB-like ORF2 but not aliB-like ORF1, but these were shown not to be pneumococci [15].

The observation that several distinct clonal lineages lacking the capsule operon have been in circulation for decades and are not derived from encapsulated strains has raised the question of how different is the genome of these strains compared to encapsulated pneumococci $[5,8]$. The aim of this study was to characterise a carriage collection of NT circulating in Portugal in a period of 11 years to obtain insights into the genetic basis of nontypeability and their genomic content and diversity.

\section{Results}

\section{Capsular region of NT}

To obtain insights into the genetic basis of non-typeability, the capsular region was characterised for a set of $42 \mathrm{NT}$ strains representative of the lineages detected in crosssectional colonisation studies conducted in Portugal among children between 1997 and 2007 (Table 1). Amplification of this region yielded, in all strains, a fragment of $6,000-8,500 \mathrm{bp}$. To investigate the heterogeneity of the capsular region, restriction fragment length polymorphism (RFLP) patterns were determined by digestion with HinfI. Nine different patterns could be distinguished after digestion with HinfI (Figure 1, Table 1). We then selected 13 isolates, representative of the different capsular RFLP patterns found in each $\mathrm{CC}$, for sequencing. The findings are summarised in Figure 2 that shows a schematic organisation of the locus compared to strains previously described by Hathaway, et al. [17]. All strains had aliB-like ORF1, aliB-like ORF2, and capN-like regions; eight had the doc-like region between capN-like and aliA. Based on the classification previously proposed by Park, et al. [15], the strains were therefore classified as belonging to $c p s$ type NCC2a (eight isolates containing the doc-like region) or NCC2b (the remaining five isolates). Of the eight strains belonging to cps type NCC2a, two had an insertion of a tnp region of $\sim 1.7 \mathrm{~kb}$ between $\operatorname{dex} B$ and aliB-like ORF1 previously described $[15,16]$.

\section{Candidate core genome}

To determine if the genome content of NT strains is comparable to that of encapsulated strains, 34 NT representing the diversity of profiles identified by PFGE, MLST, and characterisation of the capsular region, were characterised by CGH using an array that covers the genome of nine encapsulated pneumococcal strains and R6 (a non-encapsulated derivative of D39) (Additional file 1). From the 3,052 genes present in the array, 1,666 (54.6\%) were present in all NT tested, 839 (27.5\%) were present in some, and 547 (17.9\%) were absent in all (Additional file 2). In an independent analysis, conducted in the framework of an ongoing study, 180 encapsulated strains were analysed by CGH. These strains were representative of 20 serotypes and included all strains in the array (except R6). Results from this analysis were used for comparison. In this collection, 1,654 genes (54.2\%) were present in all strains, the same proportion found for the NT isolates. Of these 1,654 genes, 1,499 (90.6\%) were also present in all NT isolates (Additional file 2). Among the remaining 155 genes, 149 were present in some (but not all) NT and only 6 were absent in all. The proportion of these 155 genes present in the NT strains ranged between $80.0 \%$ and 58.7\% (Additional file 3). The 149 genes with variable presence among NT strains could be grouped into the following functions: $22.8 \%$ cellular metabolism, $16.1 \%$ transporters, $8.7 \%$ DNA metabolism, $7.4 \%$ phages and mobile elements, $2.0 \%$ surface proteins, $2.0 \%$ signalling and communication, and $41.0 \%$ were annotated as hypothetical proteins. The six genes absent in all NT were SP_0346 (annotated as capsular polysaccharide biosynthesis protein 
Table 1 Study collection and characteristics of the strains

\begin{tabular}{|c|c|c|c|c|c|c|c|c|c|}
\hline $\mathrm{CC}^{\mathrm{a}}$ & Strain & Year & PFGE & MLST & $\begin{array}{l}\text { Antibiotype } \\
\text { (non susceptible to) }^{\text {b }}\end{array}$ & $\mathrm{CSP}^{\prime}$ ComD $^{\mathrm{c}}$ & $\begin{array}{l}\text { Capsular } \\
\text { region RFLP }\end{array}$ & $\begin{array}{l}\text { Capsular region } \\
\text { sequenced }\end{array}$ & $\begin{array}{l}\text { Analysis } \\
\text { by CGH }\end{array}$ \\
\hline \multirow[t]{27}{*}{344} & PT944 & 2001 & NT1 & 344 & PG, Ery, Da, Tet, SXT & $2 / 2$ & A & Yes & Yes \\
\hline & LGST142 & 2000 & NT1 & 344 & Ery, Da, Tet, SXT & $2 / 2$ & A & No & No \\
\hline & PT191 & 2001 & NT1 & 344 & PG, Ery, Da, Tet, SXT & $2 / 2$ & A & No & No \\
\hline & PT3412b & 2002 & NT1 & 344 & Ery, Da, Tet, SXT & $2 / n d$ & A & No & No \\
\hline & PT998 & 2001 & NT1 & 344 & PG, Ery, Tet, SXT & $2 / n d$ & A & No & No \\
\hline & LGST214 & 2000 & ND & 344 & Ery, Tet, SXT & $2 / n d$ & A & No & No \\
\hline & DCC2367 & 1999 & NT1 & 344 & PG, Tet, SXT & $2 / 2$ & $\mathrm{~F}$ & Yes & No \\
\hline & РТ389 & 2001 & NT1 & 344 & PG, Tet, SXT & $2 / n d$ & $\mathrm{~F}$ & No & No \\
\hline & РT4427a & 2002 & NT1 & 344 & PG, Ery, Tet, SXT & $2 / \mathrm{nd}$ & $\mathrm{H}$ & Yes & No \\
\hline & WL212 & 2001 & NT1 & 1619 & PG, Ery, Da, SXT & $2 / 2$ & A & No & Yes \\
\hline & PT5899 & 2007 & NT1 & 5220 & PG, Ery, Tet, SXT & $2 / n d$ & nd & No & Yes \\
\hline & DCC635 & 1997 & NT2 & 344 & PG, Ery, Da, Tet, SXT & $2 / 2$ & A & No & Yes \\
\hline & WL992 & 2002 & NT3 & 344 & PG, Ery, Da, Tet, SXT & $2 / 2$ & A & No & Yes \\
\hline & PT2987 & 2002 & NT4 & 344 & PG, Ery, Da, Tet, SXT & $2 / n d$ & A & No & No \\
\hline & PT2293b & 2001 & NT4 & 344 & PG, Ery, Da, Tet, SXT & $2 / 2$ & $E$ & Yes & Yes \\
\hline & PT6317 & 2007 & NT5 & 344 & PG, Ery, Da, Tet, SXT & $2 / n d$ & nd & No & Yes \\
\hline & PT5838b & 2007 & NT6 & 344 & Ery, Da, Tet, SXT & $2 / n d$ & nd & No & Yes \\
\hline & WL1514 & 2003 & NT7 & 344 & PG, Ery, Da, Tet, SXT & $2 / 2$ & A & No & Yes \\
\hline & PT6318 & 2007 & NT7 & 4586 & PG, Ery, Da, Tet, SXT & $2 / n d$ & nd & No & Yes \\
\hline & PT5269 & 2006 & NT8 & 344 & PG, Ery, Da, Tet, SXT & $2 / n d$ & nd & No & Yes \\
\hline & DCC2879 & 1999 & NT9 & 897 & PG, Ery, Da, Tet, SXT & $2 / 2$ & A & No & Yes \\
\hline & PT1571b & 2001 & NT10 & 344 & PG, Ery, Da, Tet, SXT & $2 / 2$ & A & No & Yes \\
\hline & PT5727 & 2006 & NT11 & 344 & PG, Ery, Da, Tet, SXT & $2 / n d$ & nd & No & Yes \\
\hline & PT5082a & 2003 & NT22 & 344 & PG, Ery, Da, Tet, SXT & $2 / n d$ & 1 & No & No \\
\hline & WL598 & 2001 & NT25 & 344 & PG, Tet, SXT & $2 / n d$ & $\mathrm{~F}$ & No & No \\
\hline & DCC1795 & 1998 & NT26 & 1541 & PG, Ery, Da, Tet, SXT & $2 / 2$ & A & No & Yes \\
\hline & DCC2435p & 1999 & ND & 344 & Ery, Da, Tet, SXT & $2 / n d$ & A & No & No \\
\hline \multirow[t]{12}{*}{1156} & PT268 & 2001 & NT21 & 1156 & PG, Ery, Da, Tet, SXT & $1 / \mathrm{nd}$ & A & No & No \\
\hline & PT6210 & 2007 & NT21 & 4583 & PG, Ery, Da, Tet, SXT & $1 / \mathrm{nd}$ & nd & No & Yes \\
\hline & PT2687b & 2001 & NT22 & 1156 & PG, Ery, Da, Tet, SXT & $1 / \mathrm{nd}$ & A & No & No \\
\hline & PT5561 & 2006 & NT22 & 1156 & PG, Ery, Da, Tet, SXT & $1 / \mathrm{nd}$ & nd & No & Yes \\
\hline & PT4014 & 2002 & NT22 & 1153 & PG, Ery, Da, Tet, SXT & $1 / 1$ & C & No & Yes \\
\hline & PT4222 & 2002 & NT24 & 1156 & PG, Ery, Da, Tet, SXT & $1 / 1$ & A & No & No \\
\hline & PT5002 & 2003 & NT24 & 1156 & Ery, Da, Tet & $1 / 1$ & A & No & Yes \\
\hline & PT1493 & 2001 & NT24 & 1617 & $P G, S X T$ & $1 / 1$ & A & Yes & Yes \\
\hline & WL352.1 & 2001 & NT24 & 1703 & $P G, S X T$ & $1 / 1$ & A & No & Yes \\
\hline & PT3201 & 2002 & NT24 & 1153 & PG, Ery, Da, Tet, SXT & $1 / 1$ & C & Yes & Yes \\
\hline & PT6209b & 2007 & NT24 & 4583 & PG, Ery, Da, Tet & $1 / \mathrm{nd}$ & nd & No & Yes \\
\hline & PT2322 & 2001 & ND & 1153 & PG, Ery, Da, Tet, SXT & $1 / \mathrm{nd}$ & C & No & No \\
\hline 320 & PT1804b & 2001 & NT19 & 888 & $P G, S X T$ & $1 / 1$ & A & Yes & Yes \\
\hline $1540^{*}$ & PT1718 & 2001 & NT12 & 1540 & SXT & $1 / 4$ & A & Yes & Yes \\
\hline $1278^{*}$ & PT4812 & 2003 & NT22 & 1278 & $P G, S X T$ & $1 / 1$ & A & Yes & Yes \\
\hline 941 & DCC2787 & 1999 & NT13 & 941 & SXT & $2 / 2$ & B & Yes & Yes \\
\hline
\end{tabular}


Table 1 Study collection and characteristics of the strains (Continued)

\begin{tabular}{|c|c|c|c|c|c|c|c|c|c|}
\hline & WL165b & 2001 & NT13 & 1704 & & $2 / 2$ & $B$ & No & Yes \\
\hline & DCC2648 & 1999 & NT14 & 941 & SXT & $2 / 2$ & B & No & Yes \\
\hline \multirow[t]{4}{*}{448} & WL850a & 2002 & NT15 & 448 & & $2 / 2$ & B & Yes & Yes \\
\hline & WL1084 & 2002 & NT15 & 448 & & $2 / 2$ & B & No & No \\
\hline & PT2417 & 2001 & NT15 & 448 & $P G, S X T$ & $2 / n d$ & B & No & No \\
\hline & WL108 & 2001 & NT16 & 448 & & $2 / n d$ & nd & No & Yes \\
\hline \multirow[t]{2}{*}{1618} & PT673 & 2001 & NT17 & 1618 & PG, Ery & $1 / 1$ & D & Yes & Yes \\
\hline & WL402.1b & 2001 & NT17 & 1618 & PG, Ery, Da, Tet, SXT & $1 / 1$ & D & No & Yes \\
\hline $1705^{*}$ & WL977 & 2002 & NT23 & 1705 & $P G, S X T$ & $1 / 1$ & G & Yes & Yes \\
\hline
\end{tabular}

a - clonal complex (CC); singleton $\left(^{*}\right)$; b - penicillin G (PG), erythromycin (Ery), clindamycin (Da), tetracycline (Tet), and trimethoprim sulfamethoxazole (SXT); c - ComD2 had an E151K substitution and ComD4 had an M77I and an E151K substitutions, both outside the sensor domain of ComD; nd - not determined.

Cps4A), SP_0368 (cell wall surface anchor family protein), SP_1153 (hypothetical protein), SP_2157 (alcohol dehydrogenase, iron-containing), SP_2158 (L-fucose isomerase), and SP_2168 (fucose operon repressor, putative).

Furthermore, NT isolates contained between 2,049 and 2,120 genes detected by $\mathrm{CGH}$ with an average of 2,095 genes, while the 180 encapsulated strains had between 2,119 and 2,306 genes with an average of 2,235. Based on these experiments, although the size of "core" genomes of NT versus encapsulated strains was comparable, NT strains characterised in this study had 6.3\% less genes detected by $\mathrm{CGH}$ than encapsulated strains.

\section{Accessory regions (ARs)}

To further analyse the genome content of NT strains, the presence of previously identified accessory regions was investigated (Figure 3) [19]. Of the 41 accessory regions described to date, 17 were present or partially present in all NT strains analysed (ARs 3, 6, 9, 13-15, 18, 20-22, 31-33, 35, 37-39) and 7 were absent in all (ARs 2, 5, 7, $11,30,36$, and 41). Furthermore, 8 ARs were present, or at least partially present, in most strains (ARs 1, 8, 10, $16,17,19,23,28)$ and 9 ARs were absent, or mostly absent, in most strains (ARs 4, 12, 24-27, 29, 34, and 40).

Twenty-five new ARs (named ARs 42 to 66), totalling 134 genes, were identified in this study. Their predicted

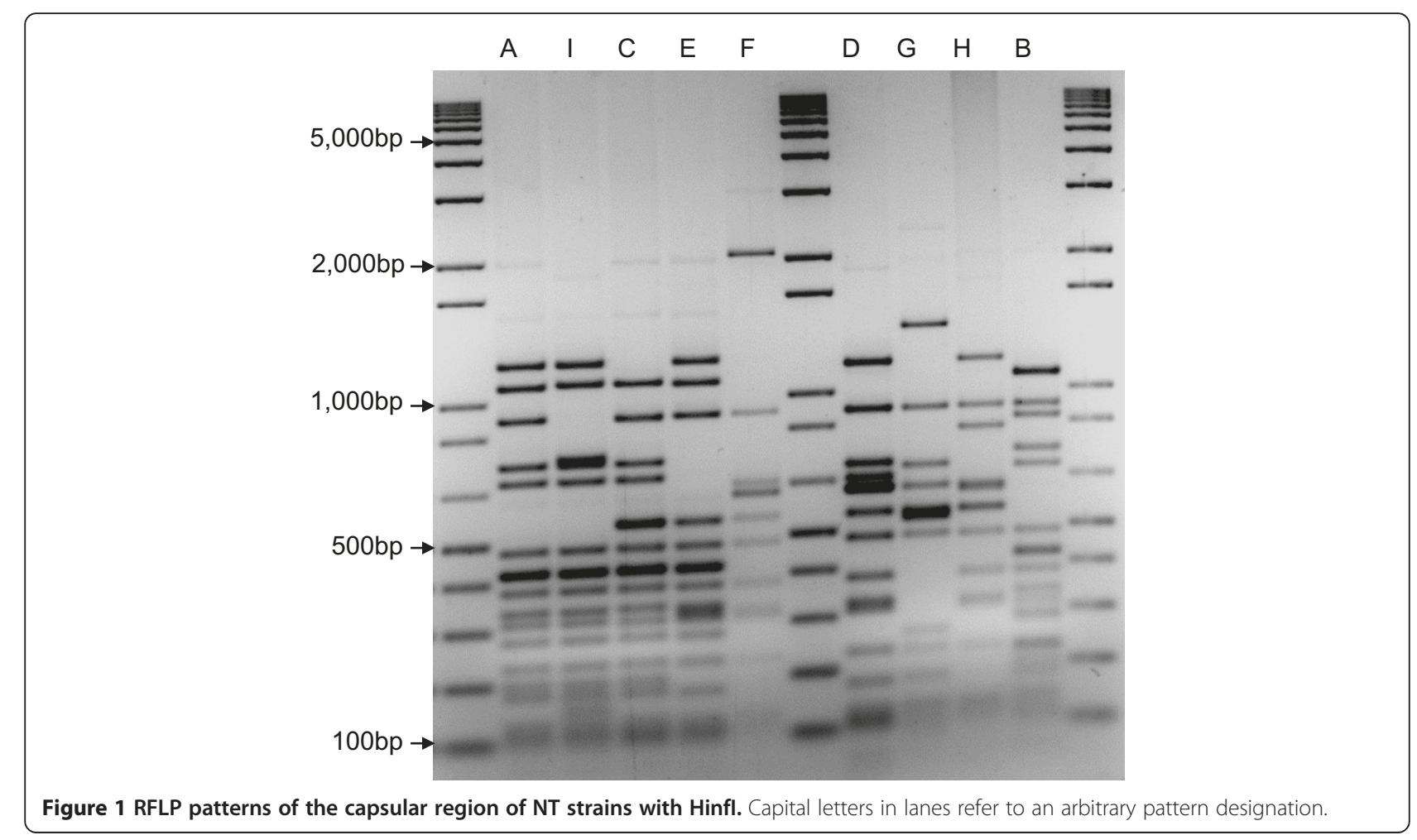




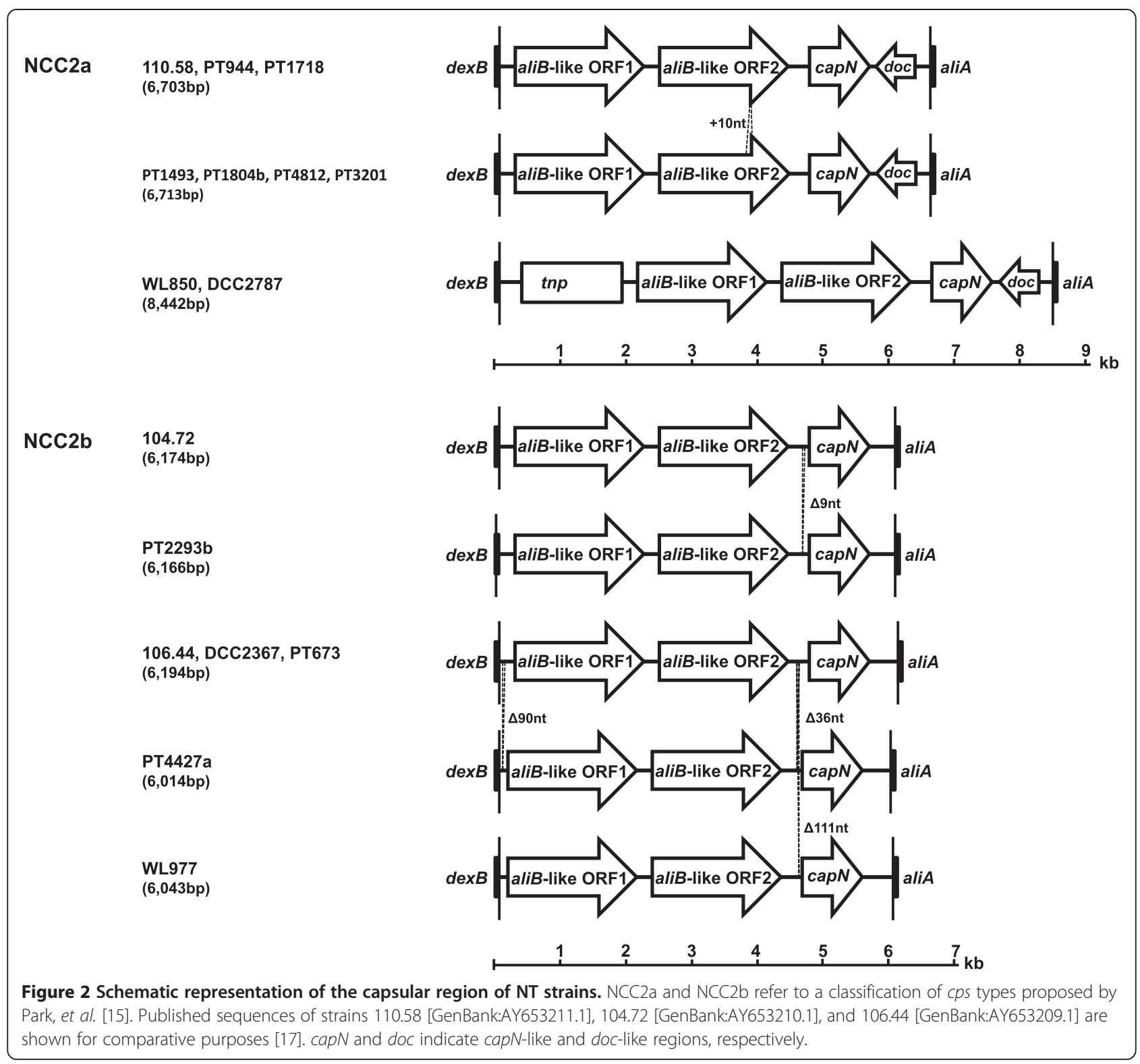

functions are described in Table 2 and include $A B C$ transporters, type II restriction-modification systems, phosphotransferase systems and proteins involved in metabolism, cell envelope, transport, and transcription regulation. These 25 ARs were dispersed around the TIGR4 genome (Figure 4). Of these, 22 ARs were present, or at least partially present, in most strains (ARs 42-54, 56-59, and 61-65), 2 ARs were absent, or mostly absent, in most strains (ARs 55 and 60), and AR66 (encoding for hypothetical proteins) was absent in all.

Altogether, when looking for ARs absent in all NT, these were found to encode for capsular genes (AR7), type-I pili (AR11), sucrose $A B C$ transporter (AR36), fucose metabolism (AR41), a putative bacteriocin (AR2), and several hypothetical proteins (ARs 5, 30 and 66).

\section{Virulence factors}

A total of 496 of the genes present on the array were identified as virulence factors of pneumococcus based on published data (annotated in Additional file 2) [20-30]. Of these, $363(73.2 \%)$ were present in all NT strains and 36 (7.3\%) were absent in all. This latter group included genes associated with capsular synthesis (TIGR4 $\operatorname{cps} A, \operatorname{cps} C$, $c p s D$, cpsE, $c p s F$, and $c p s$ ), pilus islet-1, the virulence proteins $c b p A / p s p C, p s p A$, nanE, $g l f$, and $n t p K$ among others (Additional file 2). PCR analysis of pilus islet- 1 and -2 confirmed the absence of these loci in all 52 strains.

Regarding competence-associated genes $(n=22)$, all were present in all strains, including the recently described comG operon (SP_1808 and SP_2047-53), encoding for a type-IV transformation pilus (Table 3) [31]. In addition, 


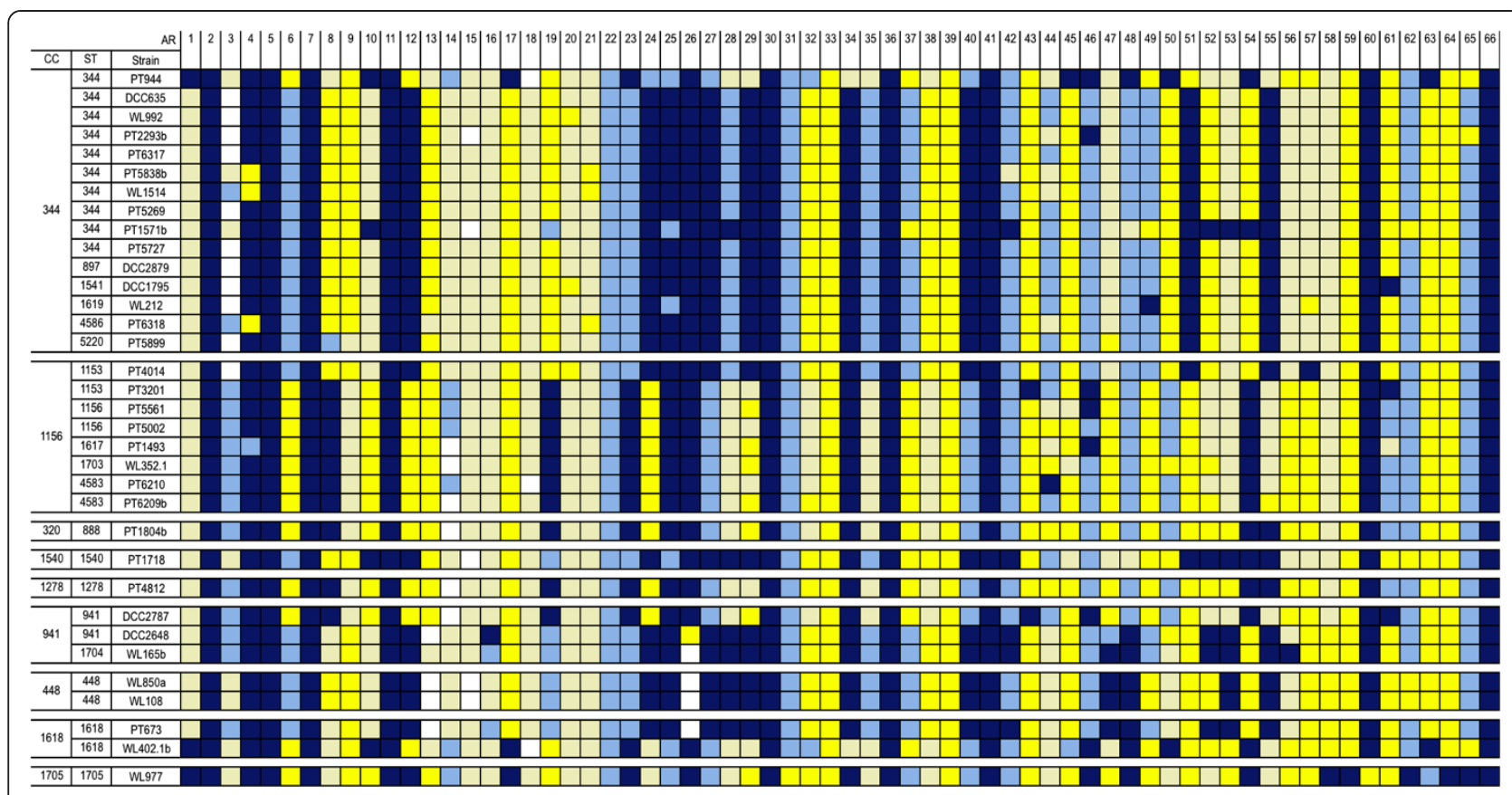

Figure 3 Distribution of accessory regions (ARs) among NT strains. Dark yellow - AR is present; light yellow - more than 50\% of the genes in the AR are present; white - 50\% of the genes in the AR are present; light blue - more than 50\% of the genes in the AR are absent; dark blue - AR is absent

$\operatorname{com} C$ and $\operatorname{comD}$ alleles were determined by PCR for the 52 NT strains included in this study and a clear distinction between CCs could be observed for comCD: CCs 344, 448, and 941 encoded CSP2 and ComD2; CCs 320, 1156, 1278, 1618, and 1705 had CSP1 and ComD1; and CC1540 had CSP1 and ComD4 [32].

Nine choline binding proteins have been implicated in virulence, and all were present on the array $[20,27,33,34]$. Of these, $c b p D, c b p E / p c e, l y t A$, $l y t B$, and $l y t C$ were present in all strains, with $\operatorname{cbp} A / p s p C$ and $p s p A$ being absent in all strains. Variation between CCs was found for $c b p F, c b p G$ and $p c p A$ (Table 3).

In addition, 12 genes implicated in colonisation were present on the array. Of these, pavA, eno, pyrR, strH, $\operatorname{trpG}$, rrO1, and SPY2053 were present in all NT, while $r l r A$ was absent in all strains. Clonal variation was found for genes $h y l, n a n A, \operatorname{bgaA}$, and phoU (Table 3).

Among other major virulence factors, ply, psaA, htrA, $I g A$, and $\operatorname{sp} x B$ were present in all strains with variations between clones found for the operons piuA-D and pia $A-D$ and $z m p B$.

Further details on the variable presence of virulence genes can be found in Additional file 2 .

\section{Intraclonal variation}

Comparison of SmaI-PFGE patterns of NT strains resulted in an unexpected high diversity of profiles for strains belonging to the same ST (Figure 5) [5]. Likewise, there were also strains with similar PFGE profiles belonging to different STs. This lack of concordance was puzzling, as previous studies have found a good general agreement with PFGE and MLST for encapsulated pneumococci [35]. To investigate possible genomic variations that could account for the lack of concordance found between PFGE and MLST results, CGH results were compared for strains belonging to the same $\mathrm{CC}$. For any given $\mathrm{CC}$, all strains analysed shared at least $72 \%$ of the genes detected in the NT pool (Figure 6).

When we looked at intraclonal diversity, within each $\mathrm{CC}$, variation between strains was mostly due to only a few (if any) genes. Still, exceptions were found: strains PT944 of CC344, PT4014 of CC1156, and DCC2787 of CC941 had 162, 144, and 244 genes, respectively, uniquely present in their genomes compared to other strains of the same CC. Also, the two strains of CC1618 were found to differ from each other in more than 400 genes.

When looking for the functions of genes uniquely present in one strain of a given $\mathrm{CC}$, most were found to encode for hypothetical proteins (51.3\%). Other genes had the following functions: transport and secretion (13.4\%), cell metabolism (9.9\%), phages and mobile elements (9.5\%), DNA metabolism (7.8\%), cell wall, cell membrane, and cell division (3.8\%), signalling and communication $(2.7 \%)$, and stress (1.5\%). Furthermore, only $10.2 \%$ of this latter group of genes have been described as virulence genes. Not surprisingly, close to half of these genes were found in ARs (44.4\%). 
Table 2 New accessory regions found in NT strains

\begin{tabular}{|c|c|c|c|}
\hline Accessory region & TIGR4 locus & Identified by STM ${ }^{a}$ & Predicted function $^{b}$ \\
\hline 42 & SP_0115-0117 & Yes & Cell envelope \\
\hline 43 & SP_0124-0126 & No & Hypothetical \\
\hline 44 & SP_0130-0144 & Yes & ABC transporter (glucose) \\
\hline 45 & SP_0314-0330 & Yes & PTS system \\
\hline 46 & SP_0367-0369 & No & Cell envelope \\
\hline 47 & SP_0391-0393 & No & Cell envelope \\
\hline 48 & SP_0569-0571 & Yes & Type II RM system \\
\hline 49 & SP_0595-0597 & Yes & Hypothetical \\
\hline 50 & SP_0627-0629 & No & Hypothetical \\
\hline 51 & SP_0636-0640 & No & $A B C$ transporter \\
\hline 52 & SP_0683-0685 & No & Hypothetical \\
\hline 53 & SP_0703-0711 & No & $\mathrm{ABC}$ transporter (aa) \\
\hline 54 & SP_0737-0740 & No & Transport \& transcription regulation \\
\hline 55 & SP_1030-1040 & Yes & $A B C$ transporter (iron) \\
\hline 56 & SP_1042-1045 & Yes & Metabolic \\
\hline 57 & SP_1119-1125 & Yes & Metabolic (glycogen) \\
\hline 58 & SP_1160-1165 & No & Metabolic (acetoin) \\
\hline 59 & SP_1209-1211 & No & Hypothetical \\
\hline 60 & SP_1656-1658 & No & Hypothetical \\
\hline 61 & SP_1677-1679 & No & Hypothetical \\
\hline 62 & SP_1849-1851 & No & Type II RM system \\
\hline 63 & SP_1855-1859 & Yes & Transport \& transcription regulation \\
\hline 64 & SP_1869-1872 & Yes & $A B C$ transporter (iron) \\
\hline 65 & SP_2147-2154 & No & Metabolic (arginine) \\
\hline 66 & SP_2178-2183 & Yes & Hypothetical \\
\hline
\end{tabular}

a - gene(s) within region(s) identified by signature-tagged mutagenesis as required for invasive disease [20]; b - ATP-binding cassette (ABC); phosphotransferase (PTS); restriction modification (RM); amino acid (aa).

To investigate if the high variability of PFGE types found could be due to the presence of prophages, as previously reported [36], or the presence of other mobile elements, we evaluated their distribution among NT strains (Figure 7). In some cases, e.g. NT1, NT2, and NT6 of ST344 or NT22 and NT24 of ST1153, the content of mobile elements was indeed distinct between strains, which might explain the variability found. However, in other cases, such as NT2, NT3, NT5, NT8, and NT11 of ST344 and NT15 and NT16 of ST448, the strains shared the same mobile elements. On the other hand, examples of strains belonging to the same PFGE type and ST but with different mobile elements' profiles were also observed (e.g. NT17 of ST448). To complement this analysis, the presence of prophages was also determined by lytA hybridisation (Additional file 4). In ST344, the six PFGE types tested exhibited three lytA hybridisation patterns, whereas the two ST448 PFGE types tested showed the same lytA hybridisation pattern. According to these results, the high variability of PFGE types observed within STs could not be entirely explained by the presence of prophages or other mobile elements.

\section{Discussion}

In this study we aimed to characterise the genomic content of a collection of NT strains representative of the carriage lineages circulating in Portugal in a period of 11 years (1997-2007). Strains were analysed by CGH against a panel of 10 pneumococcal strains and their capsular region was sequenced. According to their capsular regions, strains in this study could be classified as NCC2, as they all contained aliB-like genes [15]. Strains with similar capsular regions have also been identified in carriage and disease isolates circulating in Switzerland, the Netherlands, UK, USA, Brazil, South Korea, Thailand, and the Gambia [15-17,37]. In our collection we did not find isolates of cps type NCC1 (containing the $p s p K / n s p A$ gene) and we did not include NT strains derived from encapsulated lineages that had alterations in the capsular operon leading to absence of capsular production (Group I NT). 


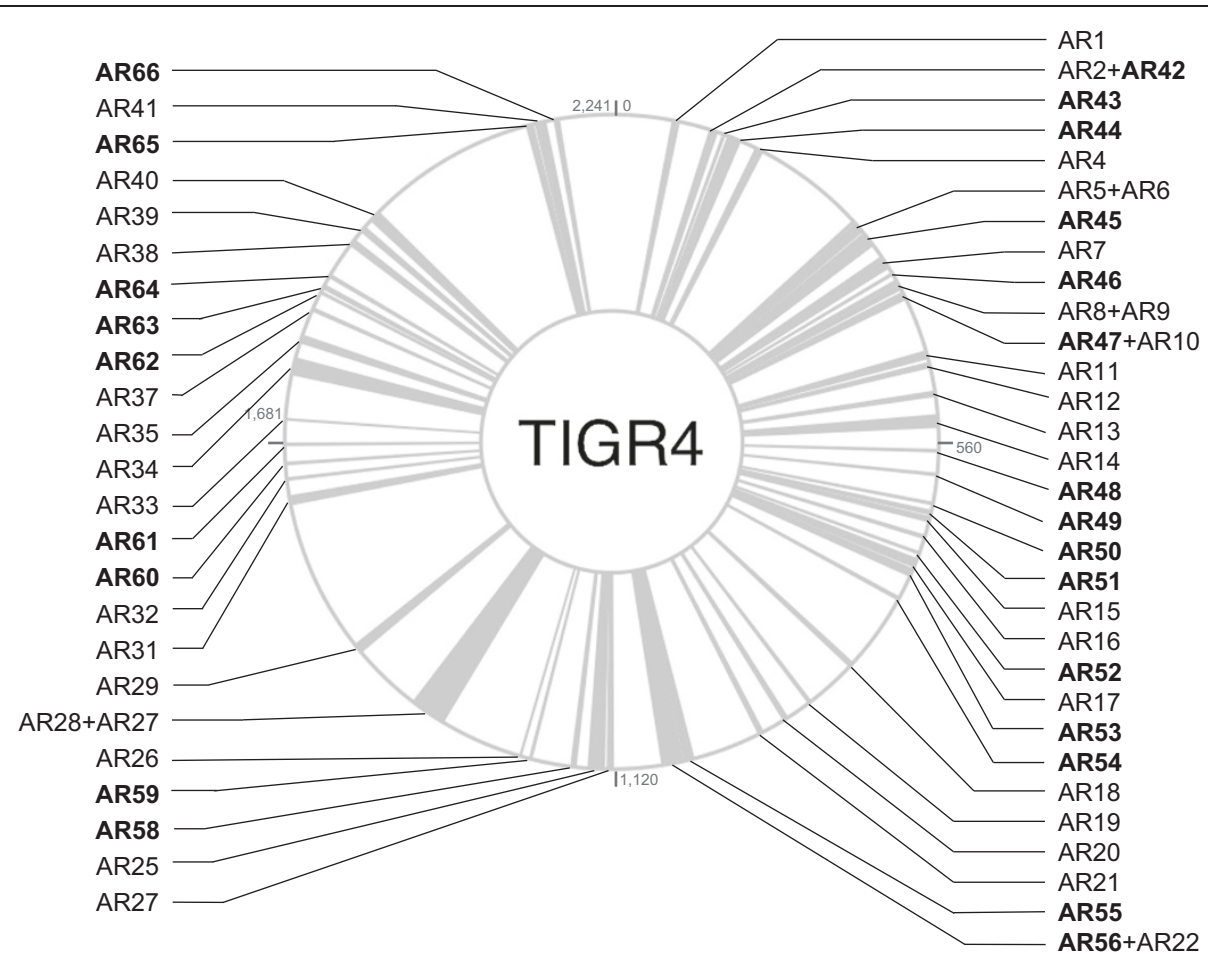

Figure 4 Distribution of 66 accessory regions (ARs) over the TIGR4 genome. Bold - new ARs identified in NT strains.

Of interest, a recent study by Park, et al. aimed to characterise invasive NT strains from the USA. The authors reported that these strains are rare, accounting for less than $1 \%$ of the invasive pneumococcal disease cases, and most are of Group I NT, with only a few cases caused by NCC2 NT. Nonetheless, it has been clearly demonstrated that NCC2 NT are capable of causing invasive disease and therefore should not be disregarded [17,37].

In relation to core genome, $54.6 \%$ of the genes represented on the array were found in all NT strains, the same proportion found for a collection of 180 encapsulated strains used for comparison (54.2\%). However, the average number of total genes detected in the NT strains $(2,095)$ was $6 \%$ less than the corresponding value found for encapsulated strains. Still, this result should be interpreted with caution as, by using a CGH approach, NT genes were probably missed to an unknown extent.

Twenty-five new ARs, dispersed around the TIGR4 genome, were identified in this study. Of the 66 ARs identified to date, only seven were absent in all NT and encoded for genes associated with sugar metabolism, capsular synthesis, type-I pilus, and hypothetical proteins [19]. Also, more than $90 \%$ of the virulence factors identified in pneumococcus were found in NT. The most relevant virulence factors absent from all NT were the capsular genes and type-I pilus (referred to above), type-II pilus, choline-binding protein $\mathrm{A}(\operatorname{cbp} A / p s p C)$, and pneumococcal surface protein A ( $p s p A)$ [23]. Also absent in the majority of NT was the major iron $\mathrm{ABC}$ transport system piaA-D. However, piuA-D, a second iron $\mathrm{ABC}$ transport system, was present in the majority of NT. Mutations in these systems have been shown to result in mild (piuA-D) to moderate (piaA-D) reduction in virulence [38]. Together with the lack of capsule and other important virulence genes, the absence of these genes in NT should contribute to a lower propensity of NT to cause disease.

As expected, all strains had all competence genes, including the newly described transformation pilus $[14,31,39]$. According to the type of competence stimulating peptide (CSP, encoded by $\operatorname{com} C$ ) secreted by pneumococcal strains, strains can be divided in pherotypes. The dominant pneumococcal pherotypes are CSP1 and CSP2, respectively found in $60-75 \%$ and $25-40 \%$ of carriage or clinical isolates $[40,41]$. In NT, the dominant pherotype was CSP2 (65\% of the strains), with the remaining strains belonging to pherotype CSP1. In our study, pherotype was a clonal property, with all strains within a CC belonging to the same pherotype. The same association was previously observed in encapsulated pneumococcus [42]. These results further support that NT are bona-fide pneumococci, in contrast with atypical strains of ambiguous speciation, where multiple ComC alleles can be found [43].

To explore the reasons underlying the observation that NT had highly variable PFGE profiles in contrast to 
Table 3 Virulence factors determined by CGH for NT clonal complexes

Gene name and/or annotation
Competence proteins
comA; competence factor transporting ATP-bin
permease protein ComA
comB; competence factor transport protein Co
comD; putative sensor histidine kinase ComD
comE; response regulator ComE
comX1; transcriptional regulator ComX1
competence damage-inducible protein A
coiA; competence protein CoiA
competence protein ComF, putative
celA; competence protein CelA
celB; competence protein CelB
ccs 1 ; competence-induced protein Ccs1
ccs4; competence-induced protein Ccs4
ccs16; competence-induced protein Ccs16
cspC-related protein, authentic point mutation
pilD; type IV prepilin peptidase, putative
comGA/cglA; competence protein CglA
comGB/cglB; competence protein CglB
comGC/cglC; competence protein CglC
comGD/cglD; competence protein CgID
comGE
comGF
comGG

comA; competence factor transporting ATP-binding/ permease protein ComA

comB; competence factor transport protein ComB

comD; putative sensor histidine kinase ComD

coiA; competence protein CoiA

Choline-binding proteins

cbpA/pspC; choline binding protein A

$c b p D$; choline binding protein D

cbpE/pce; choline binding protein $\mathrm{E}$

$c b p F$; choline binding protein $\mathrm{F}$

cbpG; choline binding protein $\mathrm{G}$

IytA; autolysin

IytB; endo-beta- $\mathrm{N}$-acetylglucosaminidase

lyt $C$; beta-N-acetylhexosaminidase

pspA; pneumococcal surface protein A

$p с p A$; choline binding protein PcpA

Colonisation-associated proteins

hyl; hyaluronidase

nanA; neuraminidase $\mathrm{A} /$ siliase $\mathrm{A}$ precursor

pavA; adherence and virulence protein $\mathrm{A}$

rlrA; transcriptional regulator, putative

bgaA; beta-galactosidase

eno; phosphopyruvate hydratase

pyrR; bifunctional pyrimidine regulatory protein PyrR uracil phosphoribosyltransferase 


\section{Table 3 Virulence factors determined by CGH for NT clonal complexes (Continued)}

\begin{tabular}{|c|c|c|c|c|c|c|c|c|c|}
\hline strH; beta-N-acetylhexosaminidase & 1 & 1 & 1 & 1 & 1 & 1 & 1 & 1 & 1 \\
\hline $\operatorname{trpG;}$ anthranilate synthase component II & 1 & 1 & 1 & 1 & 1 & 1 & 1 & 1 & 1 \\
\hline $\begin{array}{l}\text { phoU; phosphate transport system regulatory protein } \\
\text { PhoU, putative }\end{array}$ & 0.1 & 0.9 & 1 & 1 & 1 & 0.3 & 0 & 0.5 & 0 \\
\hline rr01; DNA-binding response regulator & 1 & 1 & 1 & 1 & 1 & 1 & 1 & 1 & 1 \\
\hline transcriptional regulator SPY2053 & 1 & 1 & 1 & 1 & 1 & 1 & 1 & 1 & 1 \\
\hline \multicolumn{10}{|l|}{ Other major virulence factors } \\
\hline ply; pneumolysin & 1 & 1 & 1 & 1 & 1 & 1 & 1 & 1 & 1 \\
\hline $\begin{array}{l}\text { psaA; manganese } \mathrm{ABC} \text { transporter, manganese-binding } \\
\text { adhesion lipoprotein }\end{array}$ & 1 & 1 & 1 & 1 & 1 & 1 & 1 & 1 & 1 \\
\hline htrA; serine protease & 1 & 1 & 1 & 1 & 1 & 1 & 1 & 1 & 1 \\
\hline IgA; immunoglobulin A1 protease & 1 & 1 & 1 & 1 & 1 & 1 & 1 & 1 & 1 \\
\hline spxB; pyruvate oxidase & 1 & 1 & 1 & 1 & 1 & 1 & 1 & 1 & 1 \\
\hline $\begin{array}{l}\text { piaA; iron-compound } \mathrm{ABC} \text { transporter, iron } \\
\text { compound-binding protein }\end{array}$ & 0.1 & 0.9 & 0 & 0 & 0 & 0.3 & 0 & 0.5 & 1 \\
\hline piaB; iron-compound $A B C$ transporter, permease protein & 0.1 & 0.9 & 0 & 0 & 0 & 0.3 & 0 & 0.5 & 1 \\
\hline piaC; iron-compound $A B C$ transporter, permease protein & 0.1 & 0.9 & 0 & 0 & 0 & 0.3 & 0 & 0.5 & 1 \\
\hline piaD; iron-compound $\mathrm{ABC}$ transporter, $\mathrm{ATP}$-binding protein & 0.1 & 0.9 & 0 & 0 & 0 & 0.3 & 0 & 0.5 & 1 \\
\hline $\begin{array}{l}\text { piuA; iron-compound } \mathrm{ABC} \text { transporter, } \\
\text { iron-compound-binding protein }\end{array}$ & 1 & 1 & 1 & 1 & 1 & 1 & 1 & 1 & 0 \\
\hline piuB; iron-compound $A B C$ transporter, permease protein & 1 & 1 & 1 & 1 & 1 & 1 & 1 & 1 & 0 \\
\hline piuC; iron-compound $\mathrm{ABC}$ transporter, permease protein & 1 & 1 & 1 & 1 & 1 & 1 & 1 & 1 & 0 \\
\hline piuD; iron-compound $\mathrm{ABC}$ transporter, ATP-binding protein & 1 & 1 & 1 & 1 & 1 & 1 & 1 & 1 & 0 \\
\hline zmpB; zinc metalloprotease & 0 & 0.8 & 0 & 0 & 0 & 0.3 & 0 & 0 & 1 \\
\hline
\end{tabular}

CC - clonal complex; sing - singleton; numbers between 0 and 1 indicate the relative proportion of strains containing the gene.

relatively conserved STs, we assessed whether the presence of prophages or other mobile elements could account for these observations. Although that seemed to be the case in some strains, the presence of these mobile elements could not entirely explain the variability found in NT isolates, at least with the approaches that were used. A more detailed characterisation of phage presence, such as the prophage typing system proposed by Romero, et al., could have provided additional information but was beyond the purpose of this study $[44,45]$.

Our study has a major limitation. Information obtained by $\mathrm{CGH}$ is restricted to what is present in the array and

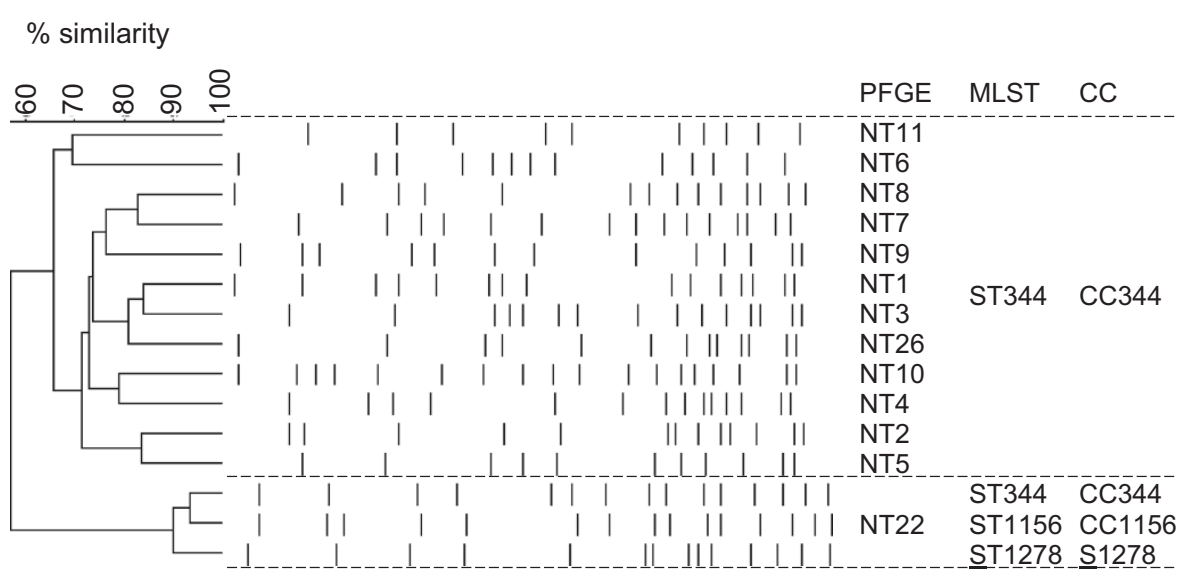

Figure 5 Comparison of PFGE patterns found for clonal complex (CC) 344, CC941, CC448, and CC1156. Dendrogram generated by UPGMA and Dice similarity with an optimisation of $1 \%$ and a tolerance of $1.5 \%$. CC - clonal complex; $S$ - singleton. 


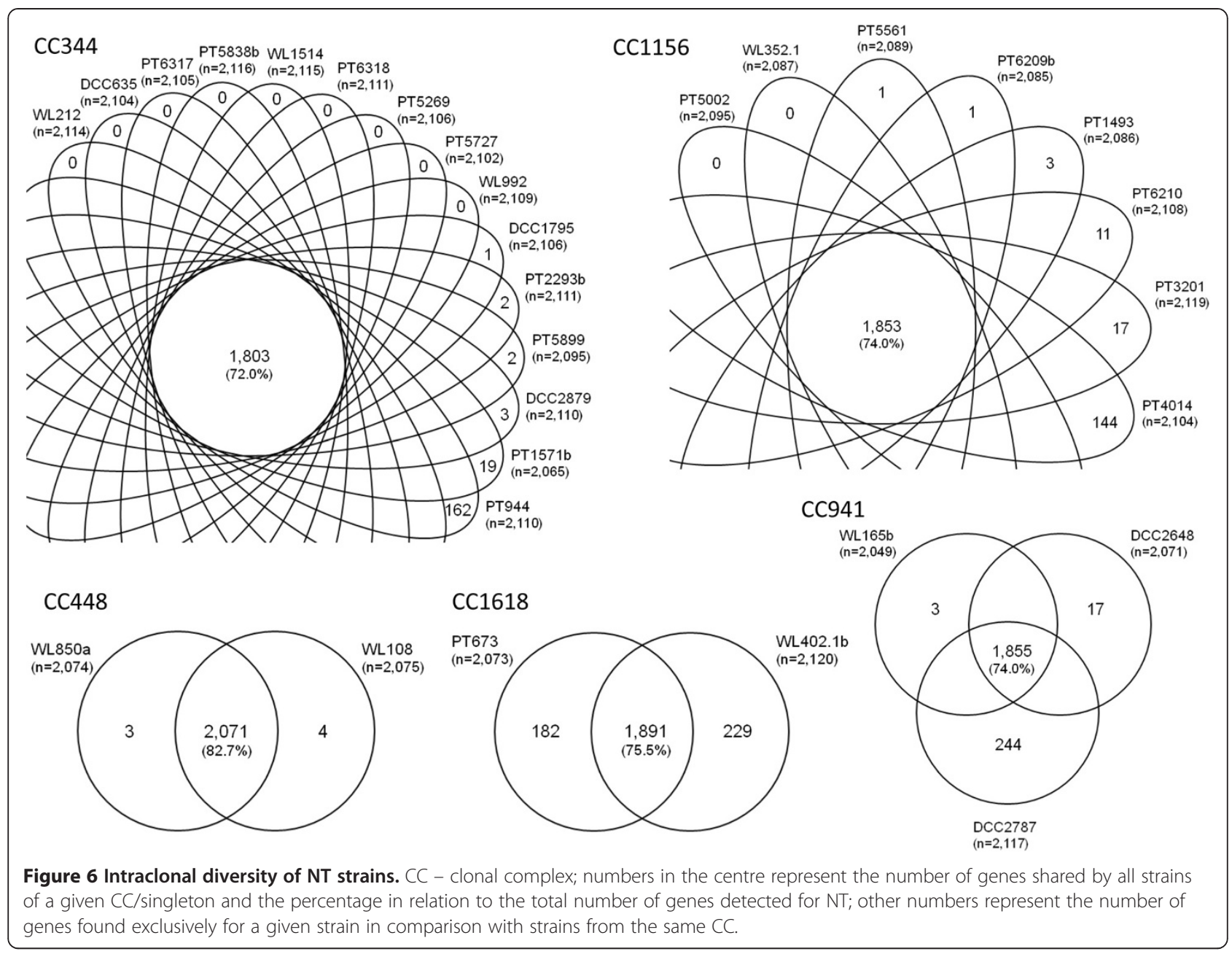

therefore limited by nature. Still, interesting information regarding variability and presence/absence of pneumococcal genes implicated in virulence was obtained, providing further hypothesis related to the low disease capacity of these strains. Our study has also some strengths. The thorough characterisation of a representative collection of NT circulating in Portugal for over a decade provided insight on the most frequent features of the lineages in circulation and definitely supported the inclusion of these strains as part of the pneumococcal population.

\section{Conclusions}

NT circulating in Portugal are a homogeneous group belonging to cps type NCC2. Our observations support that this group are bona-fide pneumococcal isolates that do not express the capsule but are otherwise essentially similar to encapsulated pneumococci, having a comparable core genome and most virulence factors. Given that NT are not targeted by current pneumococcal vaccines and that they are highly transformable, we recommend that these isolates are routinely identified and reported in surveillance studies monitoring pneumococcal serotype evolution.

\section{Methods}

\section{Ethics statement}

Approval for the original studies [5,46,47] was obtained from the Ministry of Education. The studies were registered and approved at the Health Care Centre of Oeiras that reports to Administração Regional de Saúde (ARS; "Regional Health Administration") of Lisboa and Vale do Tejo from the Ministry of Health. Signed informed consent was obtained from parents/guardians of participating children. All samples were coded numerically upon collection and processed anonymously. In the present study, only bacterial isolates were characterised (no human subjects, human material or human data were used). Thus, ethical approval was not required.

\section{Study collection}

We selected 52 NT strains for detailed characterisation. This collection was extracted from a total of 422 NT 


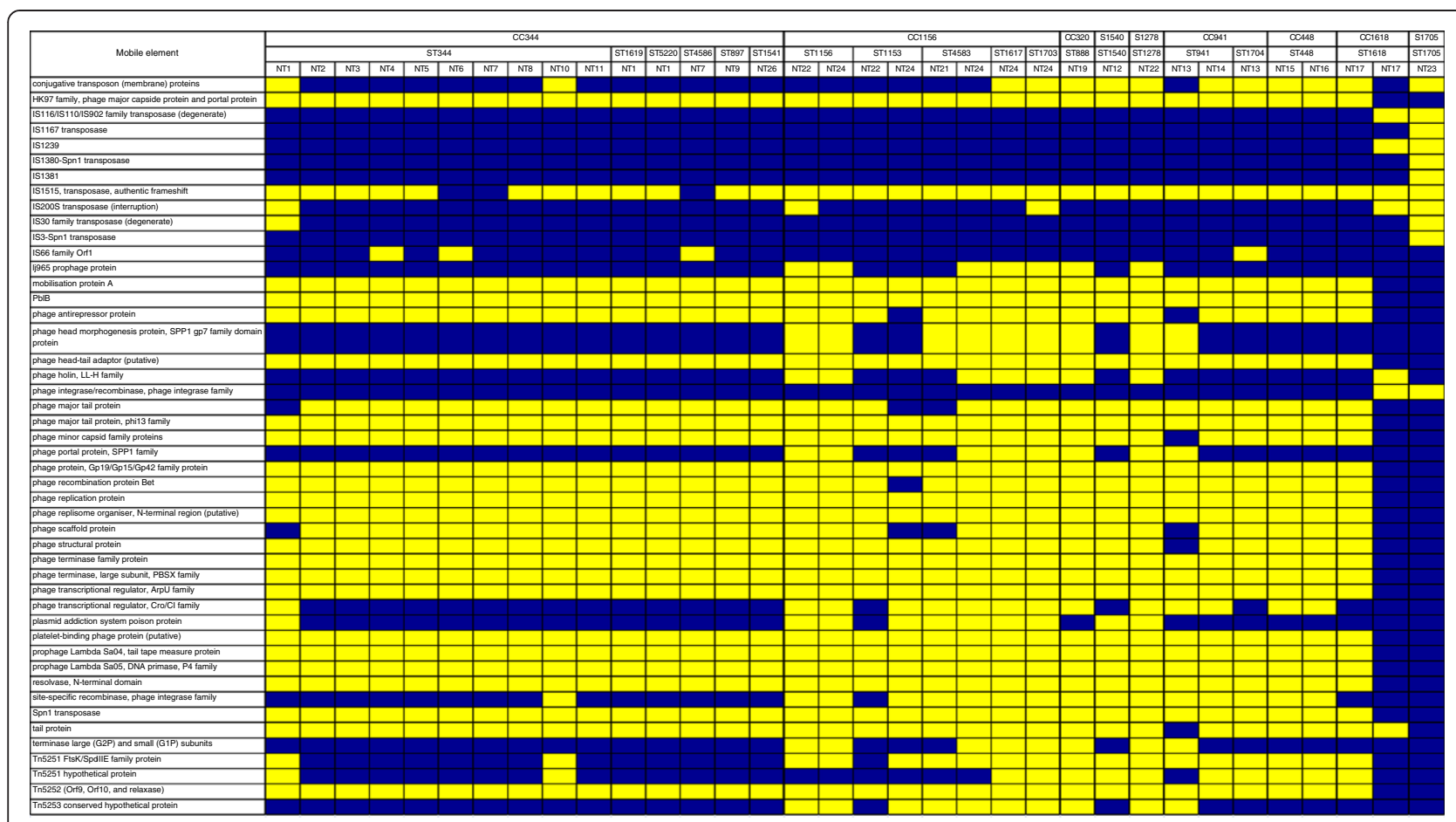

Figure 7 Intraclonal variability of mobile elements. NT1 to NT24 refer to PFGE patterns. Yellow - present; blue - absent.

strains isolated between 1997 and 2007 from the nasopharynx of preschool children attending day-care centres in Lisbon, Portugal. The isolates were previously characterised by PFGE, MLST, and antibiotic susceptibility to penicillin, amoxicillin, ceftriaxone, erythromycin, clindamycin, tetracycline, chloramphenicol, and trimethoprim sulfamethoxazole (SXT) $[5,46,47]$. The 52 strains characterised in this study were selected to cover the diversity of profiles observed among the 422 isolates, as determined by PFGE, MLST and antibiotyping. CCs were defined based on goeBURST classification [48].

\section{DNA extraction}

Total genomic DNA was isolated using either the DNeasy Blood \& Tissue kit (Qiagen, Hilden, Germany), or the High Pure PCR Template Preparation kit (Roche Diagnostics $\mathrm{GmbH}$, Mannheim, Germany), according to the manufacturers' recommendations.

\section{Characterisation of the capsular (dexB-aliA) region}

The $\operatorname{dex} B$-aliA region, corresponding to the capsular region in encapsulated pneumococci, was amplified by PCR using the primers described by Kilian, et al. using the following conditions: $92^{\circ} \mathrm{C}$ for $2 \mathrm{~min}$; 30 cycles of $92^{\circ} \mathrm{C}$ for $10 \mathrm{sec}, 58^{\circ} \mathrm{C}$ for $30 \mathrm{sec}$, and $68^{\circ} \mathrm{C}$ for $15 \mathrm{~min}$; and a final extension at $68^{\circ} \mathrm{C}$ for $7 \mathrm{~min}$ [49]. For a final volume of $50 \mu \mathrm{L}$, the PCR mixture contained $20 \mathrm{ng}$ of DNA, 1x Expand Long Template buffer 3 with $2.75 \mathrm{mM} \mathrm{MgCl}_{2}$
(Roche), $3.2 \mathrm{mM}$ (each) deoxynucleoside triphosphates, $0.4 \mathrm{mM}$ of each primer, and $3.75 \mathrm{U}$ of Expand Long Template enzyme mix (Roche). Amplicons were purified using ExoSAP by incubating $30 \mu \mathrm{L}$ of the PCR product with $6 \mathrm{U}$ of Exonuclease I (New England Biolabs, Ipswich, MA, USA) and 6U of Shrimp Alkaline Phosphatase (GE Healthcare, Waukesha, WI, USA) for $30 \mathrm{~min}$ at $37^{\circ} \mathrm{C}$ followed by $15 \mathrm{~min}$ at $80^{\circ} \mathrm{C}$.

RFLP signatures of the capsular region were determined after digestion of $15 \mu \mathrm{L}$ of purified PCR fragments with Hinfl or StyI for $3 \mathrm{~h}$ at $37^{\circ} \mathrm{C}$. For a total volume of $20 \mu \mathrm{L}$, $5 \mathrm{U}$ of enzyme, 1x NEBuffer (New England Biolabs), and $2 \mu \mathrm{g}$ of BSA (for StyI) were added. Results were analysed by gel electrophoresis and Bionumerics software (version 3.0, Applied Maths, Gent, Belgium). Patterns were clustered by UPGMA and a dendrogram was generated from a similarity matrix calculated using the Dice similarity coefficient with an optimisation of $0.5 \%$ and a tolerance of $1.0 \%$. RFLP patterns determined by digestion with HinfI were arbitrarily named A to $\mathrm{H}$.

Sequencing of the capsular region of representative RFLP patterns was performed by primer walking. Primers were designed using the nucleotide sequence of strain 110.58 as a template [GenBank:AY653211.1] (Additional file 5) $[17,49]$. PCR products were obtained, purified, and sent to Macrogen, Inc. (Seoul, South Korea) for sequencing. Additional primers were designed to amplify and sequence the gaps between fragments as needed. 
Sequences were analysed and aligned using the Lasergene software (DNASTAR Inc., Madison, WI, USA). Nucleotide sequences of the capsular region were further analysed by performing a nucleotide BLAST search at the National Center for Biotechnology Information Website against the nucleotide database and also against the capsular region sequences previously described for NT strains [15-17,50].

\section{CGH}

Microarrays used in this study were $12 x 135 \mathrm{~K}$ NimbleGen arrays (Roche). Labelling, hybridisation, and washing of the samples was done as recommended by the manufacturer using a NimbleGen microarray workflow (Roche): $1 \mu \mathrm{g}$ of DNA from each strain was fluorescently labelled with Cy3 Random Nonamers using the NimbleGen OneColor DNA Labeling kit, samples were hybridised to the microarray slide using the NimbleGen Hybridization System, slides were washed using the NimbleGen Wash Buffer kit, and CGH data was acquired on a NimbleGen MS 200 Scanner. Normalisation and background correction of data was done by quantile RMA analysis using the ArrayStar software (DNASTAR). A cut-off of 512 was reached by drawing a graph of frequencies of signal intensities for all strains. Genes with signal intensities of 512 or above were considered present (assigned 1) and genes with signal intensities bellow that value were considered absent (assigned -1) from a given strain.

\section{Validation of the microarray}

The microarray used was designed based on the genome sequence of 10 pneumococcal strains: TIGR4, R6, D39, BHN100, CBR206, LGST215, BHN191, BHN418, Sp14BS69, and Sp3-BS71 [51-58]. Triplicates of probes representing genes present in these strains were added sequentially resulting in 3,052 non-redundant ORFs. Nine of the 10 strains represented in the array were hybridised with it for validation. Only 16 of 3,052 (0.52\%) ORFs present in the microarray gave false negative results (Additional file 6). Most of these genes encoded for hypothetical proteins or mobile elements that might have been lost (during repeated handling). None of the 16 genes were part of the core genome, were related to virulence or located in ARs.

\section{ARs}

The presence of ARs (or regions of diversity) previously identified (reviewed in [19]) was investigated for NT strains. New ARs were identified as defined by Tettellin and Hollingshead: three or more contiguous genes in the TIGR4 genome that were absent from at least one of the analysed strains [59]. Classification of new ARs followed the nomenclature proposed by Blomberg, et al. and was done sequentially [59].

\section{Detection and characterisation of genes by PCR}

The presence of genes $\operatorname{com} C, \operatorname{com} D$, and piaA and the presence of type-I and type-II pili was assessed by PCR and characterised by sequencing when needed. ComD was amplified using primers comD_F (ATTAAAGGTGGGG AGATGAGG) and comD_R (CCAGCATAATCATG TCG), designed with TIGR4 [GenBank:NC_003028.3) and R6 [GenBank:NC_003098.1] nucleotide sequences as templates. Amplicons with an expected size of 841 bp were amplified using the following conditions: $94^{\circ} \mathrm{C}$ for $4 \mathrm{~min} ; 30$ cycles of $94^{\circ} \mathrm{C}$ for $30 \mathrm{sec}, 55^{\circ} \mathrm{C}$ for $30 \mathrm{sec}$, and $72^{\circ} \mathrm{C}$ for $1 \mathrm{~min}$; and a final extension at $72^{\circ} \mathrm{C}$ for $4 \mathrm{~min}$. For a final volume of $50 \mu \mathrm{L}$, the PCR mixture contained $1 \mu \mathrm{L}$ DNA, 1x Colorless GoTaq Flexi buffer (Promega, Madison, WI, USA), $2.5 \mathrm{mM} \mathrm{MgCl} 2,80 \mu \mathrm{M}$ (each) deoxynucleoside triphosphates, $0.4 \mathrm{mM}$ of each primer, and 2.5U of GoTaq DNA polymerase. Amplicons were purified using ExoSAP as described above, sent to Macrogen for sequencing, and analysed by using Lasergene software. The presence of $\operatorname{com} C$ was assessed as described by Whatmore, et al. or Carrolo, et al. [40,60]; the presence of piaA was assessed as described by Whalan, et al. [61], and the presence of type-I and type-II pili as described by Zahner, et al. [62].

\section{Prophage detection by southern hybridisation of PFGE restriction profiles with a $l y t A$ probe}

Preparation of chromosomal DNA, digestion with SmaI endonuclease, and separation of DNA fragments by PFGE were carried out as previously described [63]. Southern blotting of PFGE gels with a probe for the lytA gene was performed as previously described [36].

\section{Availability of supporting data}

Microarray data supporting the results of this article have been submitted to NCBI Gene Expression Omnibus (GEO) archive repository [64]. The GEO Series Accession Number is GSE58329.

\section{Additional files}

\footnotetext{
Additional file 1: Strains represented in the array.

Additional file 2: Core genome, virulence genes, and accessory regions. a - annotations for: TIGR4 (SP_), D39 (SPN_), R6 (spr), CBR206 (CBR206_), LGST215 (DCCPN215_), Sp3-BS71 (SP3_), Sp14-BS69 (SP14_), BHN100 (BHN100_), BHN191 (BHN191_), and BHN418 (BHN418_); Red - genes present in all NT strains analysed; bold - new accessory regions identified in NT strains.

Additional file 3: Percentage of the 155 genes absent in some NT but present in a group of 180 diverse encapsulated strains (see text). ST - multi-locus sequence type; CC - clonal complex.

Additional file 4: Detection of prophages by lyt $A$ hybridisation. A - Smal-PFGE patterns of strains representing ST344 and ST448; $B$ - southern blotting of the PFGE gel with a probe for lytA.

Additional file 5: Primers used to amplify the capsular region of NT strains.
} 
Additional file 6: Validation of the microarray. $a$ - R6 is a derivative of D39 and was not hybridised.

\section{Abbreviations \\ AR: Accessory region; CC: Clonal complex; CGH: Comparative genomic hybridisation; MLST: Multi-locus sequence typing; NT: Non-typeable pneumococcus; PFGE: Pulsed-field gel electrophoresis; RFLP: Restriction fragment length polymorphism; ST: Multi-locus sequence type; SXT: Trimethoprim sulfamethoxazole.}

\section{Competing interests}

The authors declare that they have no competing interests.

\section{Authors' contributions}

The study was conceived by RSL. Data acquisition, analysis and interpretation were done by DAT, ASS, HB, and RSL. PWMH, HL and RSL contributed with reagents, materials and analysis tools. The manuscript was drafted by DAT and RSL and critically revised by ASS, $\mathrm{HB}, \mathrm{PWMH}$, and $\mathrm{HL}$. All authors read and approved the final version of the manuscript.

\section{Acknowledgments}

This work was funded by Fundação para a Ciência e a Tecnologia, Portugal, through grants PTDC/BIA-MIC/64010/2006 and PTDC/BIA-BEC/098289/2008 awarded to RSL, SFRH/BD/70147/2010 awarded to DAT, and Pest-OE/EQB/ LA0004/2011 awarded to Laboratório Associado de Oeiras. The authors thank Marc J. Eleveld for technical assistance in the initial microarray experiments and Aldert Zomer for bioinformatical assistance in the array analysis. The funders had no role in the design of the study, collection, analysis, and interpretation of data, writing of the manuscript or in the decision to submit the manuscript for publication.

\section{Author details}

'Laboratory of Molecular Microbiology of Human Pathogens, Instituto de Tecnologia Química e Biológica (ITQB) António Xavier, Universidade Nova de Lisboa (UNL), Oeiras, Portugal. ${ }^{2}$ Laboratory of Paediatric Infectious Diseases, Radboud University Nijmegen Medical Centre, Nijmegen, the Netherlands. ${ }^{3}$ Crucell - Johnson and Johnson, Leiden, the Netherlands. ${ }^{4}$ Laboratory of Molecular Genetics, ITQB, UNL, Oeiras, Portugal. ${ }^{5}$ Laboratory of Microbiology and Infectious Diseases, The Rockefeller University, New York, NY, USA

Received: 16 May 2014 Accepted: 29 September 2014

Published: 6 October 2014

\section{References}

1. Bentley SD, Aanensen DM, Mavroidi A, Saunders D, Rabbinowitsch E, Collins M, Donohoe K, Harris D, Murphy L, Quail MA, Samuel G, Skovsted IC, Kaltoft MS, Barrell B, Reeves PR, Parkhill J, Spratt BG: Genetic analysis of the capsular biosynthetic locus from all 90 pneumococcal serotypes. PLoS Genet 2006, 2:e31.

2. Kellogg JA, Bankert DA, Elder CJ, Gibbs JL, Smith MC: Identification of Streptococcus pneumoniae revisited. J Clin Microbiol 2001, 39:3373-3375.

3. Oliver MB, van der Linden MP, Kuntzel SA, Saad JS, Nahm MH: Discovery of Streptococcus pneumoniae serotype 6 variants with glycosyltransferases synthesizing two differing repeating units. J Biol Chem 2013, 288:25976-25985

4. Nuorti JP, Whitney CG: Prevention of pneumococcal disease among infants and children - use of 13-valent pneumococcal conjugate vaccine and 23-valent pneumococcal polysaccharide vaccine - recommendations of the Advisory Committee on Immunization Practices (ACIP). MMWR Recomm Rep 2010, 59:1-18

5. Sá-Leão $R$, Simões $A S$, Nunes $S$, Sousa NG, Frazão N, de Lencastre $H$ : Identification, prevalence and population structure of non-typable Streptococcus pneumoniae in carriage samples isolated from preschoolers attending day-care centres. Microbiology 2006, 152:367-376.

6. Scott JR, Hinds J, Gould KA, Millar EV, Reid R, Santosham M, O'Brien KL, Hanage WP: Nontypeable pneumococcal isolates among navajo and white mountain apache communities: are these really a cause of invasive disease? J Infect Dis 2012, 206:73-80.
7. Xu Q, Kaur R, Casey JR, Sabharwal V, Pelton S, Pichichero ME: Nontypeable Streptococcus pneumoniae as an otopathogen. Diagn Microbiol Infect Dis 2011, 69:200-204.

8. Martin M, Turco JH, Zegans ME, Facklam RR, Sodha S, Elliott JA, Pryor JH, Beall B, Erdman DD, Baumgartner YY, Sanchez PA, Schwartzman JD, Montero J, Schuchat A, Whitney CG: An outbreak of conjunctivitis due to atypical Streptococcus pneumoniae. N Engl J Med 2003, 348:1112-1121.

9. Rolo D, Simões AS, Domenech A, Fenoll A, Linares J, de Lencastre $H$ Ardanuy C, Sá-Leão R: Disease isolates of Streptococcus pseudopneumoniae and non-typeable $S$. pneumoniae presumptively identified as atypical S. pneumoniae in Spain. PLOS ONE 2013, 8:e57047.

10. Hanage WP, Kaijalainen T, Herva E, Saukkoriipi A, Syrjanen R, Spratt BG: Using multilocus sequence data to define the pneumococcus. J Bacterio/ 2005, 187:6223-6230.

11. Domenech M, Garcia E, Moscoso M: Versatility of the capsular genes during biofilm formation by Streptococcus pneumoniae. Environ Microbiol 2009, 11:2542-2555.

12. Magee $A D$, Yother J: Requirement for capsule in colonization by Streptococcus pneumoniae. Infect Immun 2001, 69:3755-3761.

13. Weiser JN, Kapoor M: Effect of intrastrain variation in the amount of capsular polysaccharide on genetic transformation of Streptococcus pneumoniae: implications for virulence studies of encapsulated strains. Infect Immun 1999, 67:3690-3692.

14. Chewapreecha C, Harris SR, Croucher NJ, Turner C, Marttinen P, Cheng L, Pessia A, Aanensen DM, Mather AE, Page AJ, Salter SJ, Harris D, Nosten F, Goldblatt D, Corander J, Parkhill J, Turner P, Bentley SD: Dense genomic sampling identifies highways of pneumococcal recombination. Nat Genet 2014, 46:305-309.

15. Park $I H$, Kim KH, Andrade AL, Briles DE, McDaniel LS, Nahm MH: Nontypeable pneumococci can be divided into multiple cps types, including one type expressing the novel gene pspK. MBio 2012, 3:e00035-12.

16. Salter SJ, Hinds J, Gould KA, Lambertsen L, Hanage WP, Antonio M, Turner P, Hermans PW, Bootsma HJ, O'Brien KL, Bentley SD: Variation at the capsule locus, cps, of mistyped and non-typable Streptococcus pneumoniae isolates. Microbiology 2012, 158:1560-1569.

17. Hathaway LJ, Stutzmann Meier P, Battig P, Aebi S, Muhlemann K: A homologue of aliB is found in the capsule region of nonencapsulated Streptococcus pneumoniae. J Bacteriol 2004, 186:3721-3729.

18. Keller LE, Jones CV, Thornton JA, Sanders ME, Swiatlo E, Nahm MH, Park IH, McDaniel LS: PspK of Streptococcus pneumoniae increases adherence to epithelial cells and enhances nasopharyngeal colonization. Infect Immun 2012, 81:173-181.

19. Blomberg C, Dagerhamn J, Dahlberg S, Browall S, Fernebro J, Albiger B, Morfeldt E, Normark S, Henriques-Normark B: Pattern of accessory regions and invasive disease potential in Streptococcus pneumoniae. J Infect Dis 2009, 199:1032-1042.

20. Hava DL, Camilli A: Large-scale identification of serotype 4 Streptococcus pneumoniae virulence factors. Mol Microbiol 2002, 45:1389-1406.

21. Obert C, Sublett J, Kaushal D, Hinojosa E, Barton T, Tuomanen El, Orihuela $\mathrm{CJ}$ : Identification of a Candidate Streptococcus pneumoniae core genome and regions of diversity correlated with invasive pneumococcal disease. Infect Immun 2006, 74:4766-4777.

22. Williams TM, Loman NJ, Ebruke C, Musher DM, Adegbola RA, Pallen MJ, Weinstock GM, Antonio M: Genome analysis of a highly virulent serotype 1 strain of Streptococcus pneumoniae from West Africa. PLOS ONE 2012 7:e26742.

23. Kadioglu A, Weiser JN, Paton JC, Andrew PW: The role of Streptococcus pneumoniae virulence factors in host respiratory colonization and disease. Nat Rev Microbiol 2008, 6:288-301.

24. Lau GW, Haataja S, Lonetto M, Kensit SE, Marra A, Bryant AP, McDevitt D, Morrison DA, Holden DW: A functional genomic analysis of type 3 Streptococcus pneumoniae virulence. Mol Microbiol 2001, 40:555-571.

25. Molzen TE, Burghout P, Bootsma HJ, Brandt CT, van der Gaast-de Jongh $C E$, Eleveld MJ, Verbeek MM, Frimodt-Moller N, Ostergaard C, Hermans PW: Genome-wide identification of Streptococcus pneumoniae genes essential for bacterial replication during experimental meningitis. Infect Immun 2011, 79:288-297.

26. Orihuela CJ, Radin JN, Sublett JE, Gao G, Kaushal D, Tuomanen El: Microarray analysis of pneumococcal gene expression during invasive disease. Infect Immun 2004, 72:5582-5596. 
27. Polissi A, Pontiggia A, Feger G, Altieri M, Mottl H, Ferrari L, Simon D: Large-scale identification of virulence genes from Streptococcus pneumoniae. Infect Immun 1998, 66:5620-5629.

28. Garbom S, Forsberg A, Wolf-Watz H, Kihlberg BM: Identification of novel virulence-associated genes via genome analysis of hypothetical genes. Infect Immun 2004, 72:1333-1340.

29. LeMessurier KS, Ogunniyi AD, Paton JC: Differential expression of key pneumococcal virulence genes in vivo. Microbiology 2006, 152:305-311.

30. Embry A, Hinojosa E, Orihuela CJ: Regions of diversity 8, 9 and 13 contribute to Streptococcus pneumoniae virulence. BMC Microbiol 2007, 7:80.

31. Laurenceau R, Pehau-Arnaudet G, Baconnais S, Gault J, Malosse C, Dujeancourt A, Campo N, Chamot-Rooke J, Le Cam E, Claverys JP, Fronzes R: A type IV pilus mediates DNA binding during natural transformation in Streptococcus pneumoniae. PLoS Pathog 2013, 9:e1003473.

32. lannelli F, Oggioni MR, Pozzi G: Sensor domain of histidine kinase ComD confers competence pherotype specificity in Streptoccoccus pneumoniae. FEMS Microbiol Lett 2005, 252:321-326.

33. Glover DT, Hollingshead SK, Briles DE: Streptococcus pneumoniae surface protein PcpA elicits protection against lung infection and fatal sepsis. Infect Immun 2008, 76:2767-2776.

34. Gosink KK, Mann ER, Guglielmo C, Tuomanen El, Masure HR: Role of novel choline binding proteins in virulence of Streptococcus pneumoniae. Infect Immun 2000, 68:5690-5695.

35. Elberse KE, Nunes S, Sá-Leão R, van der Heide HG, Schouls LM: Multiple-locus variable number tandem repeat analysis for Streptococcus pneumoniae: comparison with PFGE and MLST. PLOS ONE 2011, 6:e19668.

36. Severina E, Ramirez M, Tomasz A: Prophage carriage as a molecular epidemiological marker in Streptococcus pneumoniae. J Clin Microbiol 1999, 37:3308-3315.

37. Park IH, Geno KA, Sherwood LK, Nahm MH, Beall B: Population-based analysis of invasive nontypeable pneumococci reveals that most have defective capsule synthesis genes. PLOS ONE 2014, 9(5):e97825.

38. Brown JS, Gilliland SM, Ruiz-Albert J, Holden DW: Characterization of pit, a Streptococcus pneumoniae iron uptake ABC transporter. Infect Immun 2002, 70:4389-4398.

39. Balaban M, Battig P, Muschiol S, Tirier SM, Wartha F, Normark S, Henriques-Normark B: Secretion of a pneumococcal type II secretion system pilus correlates with DNA uptake during transformation. Proc Natl Acad Sci U S A 2014, 111:E758-E765.

40. Carrolo M, Pinto FR, Melo-Cristino J, Ramirez M: Pherotypes are driving genetic differentiation within Streptococcus pneumoniae. BMC Microbiol 2009, 9:191.

41. Valente $\mathrm{C}$, de Lencastre $\mathrm{H}$, Sá-Leão R: Pherotypes of co-colonizing pneumococci among Portuguese children. Microb Drug Resist 2012, 18:550-554.

42. Vestrheim DF, Gaustad P, Aaberge IS, Caugant DA: Pherotypes of pneumococcal strains co-existing in healthy children. Infect Genet Evol 2011, 11:1703-1708.

43. Simões AS, Sá-Leão R, Eleveld MJ, Tavares DA, Carrico JA, Bootsma HJ, Hermans PW: Highly penicillin-resistant multidrug-resistant pneumococcus-like strains colonizing children in Oeiras, Portugal: genomic characteristics and implications for surveillance. J Clin Microbiol 2010, 48:238-246.

44. Romero P, García E, Mitchell TJ: Development of a prophage typing system and analysis of prophage carriage in Streptococcus pneumoniae. Appl Environ Microbiol 2009, 75:1642-1649.

45. Romero P, Croucher NJ, Hiller NL, Hu FZ, Ehrlich GD, Bentley SD, García E, Mitchell TJ: Comparative genomic analysis of ten Streptococcus pneumoniae temperate bacteriophages. J Bacteriol 2009, 191:4854-4862.

46. Simões AS, Pereira L, Nunes S, Brito-Avô A, de Lencastre H, Sá-Leão R: Clonal evolution leading to maintenance of antibiotic resistance rates among colonizing Pneumococci in the PCV7 era in Portugal. J Clin Microbiol 2011 49:2810-2817.

47. Simões AS, Valente $C$, de Lencastre $H$, Sá-Leão R: Rapid identification of noncapsulated Streptococcus pneumoniae in nasopharyngeal samples allowing detection of co-colonization and reevaluation of prevalence. Diagn Microbiol Infect Dis 2011, 71:208-216.

48. Francisco A, Bugalho M, Ramirez M, Carriço JA: goeBURST. [http:// goeburst.phyloviz.net/]

49. Kilian M, Poulsen K, Blomqvist T, Havarstein LS, Bek-Thomsen M, Tettelin H, Sorensen UB: Evolution of Streptococcus pneumoniae and its close commensal relatives. PLOS ONE 2008, 3:e2683.
50. Basic Local Alignment Search Tool (BLAST). [http://blast.ncbi.nlm.nih. gov/Blast.cgi]

51. Baltz RH, Norris FH, Matsushima P, DeHoff BS, Rockey P, Porter G, Burgett S, Peery R, Hoskins J, Braverman L, Jenkins I, Solenberg P, Young M, McHenney MA, Skatrud PL, Rosteck PR Jr: DNA sequence sampling of the Streptococcus pneumoniae genome to identify novel targets for antibiotic development. Microb Drug Resist 1998, 4:1-9.

52. lannelli F, Pearce BJ, Pozzi G: The type 2 capsule locus of Streptococcus pneumoniae. J Bacteriol 1999, 181:2652-2654.

53. Tettelin H, Nelson KE, Paulsen IT, Eisen JA, Read TD, Peterson S, Heidelberg J, DeBoy RT, Haft DH, Dodson RJ, Durkin AS, Gwinn M, Kolonay JF, Nelson WC, Peterson JD, Umayam LA, White O, Salzberg SL, Lewis MR, Radune D, Holtzapple E, Khouri H, Wolf AM, Utterback TR, Hansen CL, McDonald LA Feldblyum TV, Angiuoli S, Dickinson T, Hickey EK: Complete genome sequence of a virulent isolate of Streptococcus pneumoniae. Science 2001, 293:498-506.

54. Browall S, Norman M, Tangrot J, Galanis I, Sjostrom K, Dagerhamn J, Hellberg C, Pathak A, Spadafina T, Sandgren A, Battig P, Franzen O, Andersson B, Ortqvist A, Normark S, Henriques-Normark B: Intraclonal variations among Streptococcus pneumoniae isolates influence the likelihood of invasive disease in children. J Infect Dis 2014, 209:377-388.

55. Hiller NL, Janto B, Hogg JS, Boissy R, Yu S, Powell E, Keefe R, Ehrlich NE, Shen K, Hayes J, Barbadora K, Klimke W, Dernovoy D, Tatusova T, Parkhill J, Bentley SD, Post JC, Ehrlich GD, Hu FZ: Comparative genomic analyses of seventeen Streptococcus pneumoniae strains: insights into the pneumococcal supragenome. J Bacteriol 2007, 189:8186-8195.

56. Hyams C, Opel S, Hanage W, Yuste J, Bax K, Henriques-Normark B, Spratt BG, Brown JS: Effects of Streptococcus pneumoniae strain background on complement resistance. PLOS ONE 2011, 6:e24581.

57. Rodrigues F, Nunes S, Sá-Leão R, Gonçalves G, Lemos L, de Lencastre H: Streptococcus pneumoniae nasopharyngeal carriage in children attending day-care centers in the central region of Portugal, in the era of 7-valent pneumococcal conjugate vaccine. Microb Drug Resist 2009, 15:269-277.

58. Sá-Leão R, Nunes S, Brito-Avô A, Alves CR, Carriço JA, Saldanha J, Almeida JS, Santos-Sanches I, de Lencastre H: High rates of transmission of and colonization by Streptococcus pneumoniae and Haemophilus influenzae within a day care center revealed in a longitudinal study. J Clin Microbiol 2008, 46:225-234.

59. Tettelin H, Hollingshead SK: Comparative Genomics of Streptococcus pneumoniae: Intrastrain Diversity and Genome Plasticity. In The Pneumococcus. Edited by Tuomanen El. Washington, D. C: ASM Press; 2004:15-29.

60. Whatmore AM, Barcus VA, Dowson CG: Genetic diversity of the streptococcal competence (com) gene locus. J Bacteriol 1999, 181:3144-3154.

61. Whalan RH, Funnell SG, Bowler LD, Hudson MJ, Robinson A, Dowson CG Distribution and genetic diversity of the $A B C$ transporter lipoproteins PiuA and PiaA within Streptococcus pneumoniae and related streptococci. J Bacteriol 2006, 188:1031-1038.

62. Zahner D, Gudlavalleti A, Stephens DS: Increase in pilus islet 2-encoded pili among Streptococcus pneumoniae isolates, Atlanta, Georgia, USA. Emerg Infect Dis 2010, 16:955-962

63. Sá-Leão R, Tomasz A, Sanches IS, Nunes S, Alves CR, Avô AB, Saldanha J, Kristinsson KG, de Lencastre H: Genetic diversity and clonal patterns among antibiotic-susceptible and -resistant Streptococcus pneumoniae colonizing children: day care centers as autonomous epidemiological units. J Clin Microbiol 2000, 38:4137-4144.

64. Gene Expression Omnibus (GEO). [www.ncbi.nlm.nih.gov/geo/]

\section{doi:10.1186/1471-2164-15-863}

Cite this article as: Tavares et al: Non-typeable pneumococci circulating in Portugal are of cps type NCC2 and have genomic features typical of encapsulated isolates. BMC Genomics 2014 15:863. 